\title{
Knowledge collaborative incentive based on inter-organizational cooperative innovation of project-based supply chain
}

\author{
Wu Guang-dong \\ Jiangxi University of Finance \& Economics, Nanchang (China)
}

gd198410@sina.cn

Received: June2012

Accepted: February 2013

\section{Abstrad:}

Purpose Within the process of project-based supply chain inter-organizational cooperative innovation, the achievement of project value-adding has been influenced by many factors like the effect level of project-based organization and the relationship within project cooperative innovation objectives etc. The purpose of this paper is to provide a reliable reference for the contractor reasonably allocate the effect level and resources between the knowledge investment and knowledge innovation stage, and realize the knowledge collaboration for project-based supply chain.

Design/methoddogy/approadr This paper employed a methodology of knowledge collaborative incentive model and example analysis based on the assumption of equal cooperation within project-based organizations from the view of maximizing project value-adding. By considering the relationships of effect cost between knowledge input and innovation stage, a knowledge collaborative incentive model for project-based supply chain inter-organizational cooperative innovation was established, and solved through the mathematic first-order and second-order approach, A simulation with example analysis were presented as a proof.

Findings: The results show that, the project management enterprise not only could achieve project value-adding maximization, but also could realize the net earnings Pareto improvement between project management enterprise and contractor by adjusting the project knowledge 
collaboration incentive intensity and implemented knowledge input-innovation coordinative incentive strategy.

Research limitations/implications: For simplification purpose, the knowledge flow in the hypothesis of the model is presented as knowledge input and knowledge innovation stage, thus it may affect the final outcome of the result.

Originality/value During the practice of construction engineering, knowledge management is becoming more and more important to achieve project value-adding. This research provides a theoretical guideline for the project-based organizations, such as the contractor and the owner, especially on how to utilize their core knowledge perfectly.

Keywards: project-based supply chain, cooperative innovation, knowledge collaboration

\section{Introduction}

Construction industry is an information and knowledge driving based business line Construction firms all over the world are increasingly being challenged by the pressure of high-cost, over schedule project and continuous growth competition. Within a competitive business environment, the ability of getting the fast and reliable knowledge is a key factor for success, and the efficient handling of organizational knowledge is particularly crucial as well (Ribeiro, 2009). Cooperation is necessary for achieving the continuous exchange of the organizational knowledge flow; herein the cooperation among project-based organizations lays the foundation of knowledge innovation. The collaborative innovation of project-based supply chain is a management mode where all project participators organized by the cooperation contract to balance interests of all parties, identify project objectives, establish perfect coordination and communication mechanisms and finally realize reasonable risk-sharing and amicable settlement of disputes (Fariborz, Fatemeh \& Maryam, 2011). In this mode, teams with different core knowledge usually establish and disband in terms of supply chain as projects proceed. These teams form the project-based organizations of supply chain and play different roles in supply chain inter-organizational collaborative innovation. The roles played by clients and contractors are particularly important (Barrett \& Sexton, 2006).

Project-based supply chains provide such environment that enables integration, trust, communication, coordination and other cooperation among project-based organizations. The flexibility of project-based organizations makes all factors under control that includes organization structure, project environment, social environment and transaction cost, these factors play a key role in building stable partnership and promoting project-based organizations to contribute their core knowledge consciously and willingness with projects 
going on, which is the best approach for making project-based supply chains with more valueadding (Waroonkun \& Stewart, 2008). As the original drive for innovation, knowledge is an essential factor in maintaining core competence of project-based supply chain, which cannot be replaced in the appreciation of project value (Demaid \& Quintas, 2006; Wu, 2011a). Supply chains provide good environment for the transfer, assimilation, conversion and economization of knowledge, given which condition project-based organizations can consciously and voluntarily offer core knowledge according to project knowledge requirement (Yim \& Kim, 2004). Therefore, the imperative problem now is how to establish the knowledge collaborative incentive mechanisms among project-based organizations. For project-based organizations, knowledge is the most valuable assets and effective knowledge configuration underpins the core process of the organizations because knowledge covers the best practice, operation and management, organization and learning, problem solving and process creation, which are hardly duplicated (Ribeiro, 2005; Renzel, 2008; Kodama, 2005). However, due to the discreteness of the construction industry and the characteristics of the temporality and dynamics of project cooperation, it is a considerable challenge to realize the interorganizational collaborative innovation of project-based supply chains (Argote, 2000). Despite the challenge, considering the significant role of knowledge for project success, more and more project-based organizations expect to draw the support of the outer resources so as to enhance their capability of converting collaborative knowledge into core competence (Sammaddar, 2006). In regard to this problem, this paper employs the work of Mohamed and Anumba (2010) and introduces the concept of knowledge flow into project-based supply chains. We define knowledge management as process conversion in which the operation environment inside organizations are set as input, the knowledge flow are divided into knowledge investment, knowledge assimilation, knowledge transmission and knowledge innovation, and suppose that project-based organizations can obtain interests from the collaborative innovation.

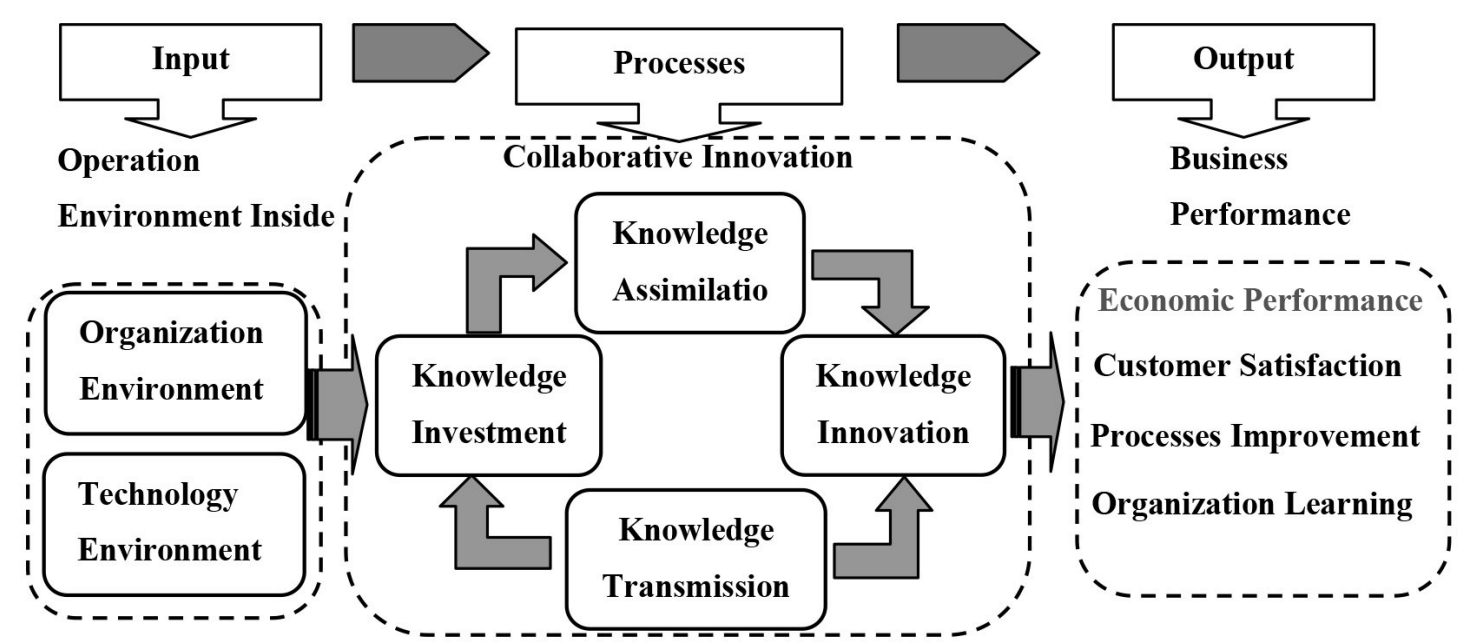

Figure 1. Processes of Inter-organizational Collaborative Innovation of Project-based Supply Chains Based on Knowledge Flow 
Based on the above discussion, it is clear that knowledge investment and knowledge innovation are the dominant processes of supply chain inter-organizational collaborative innovation. The steadiness of knowledge investment and the balance of knowledge innovation are the two important control objectives in adding project values. Since knowledge innovation needs a steady knowledge investment while knowledge investment requires proportionate knowledge innovation as a prerequisite. Both processes of knowledge investment and knowledge innovation have impacts on the realization of adding project values in different level. However, the existing research usually focus on the knowledge flow influence on project values adding from the perspective of knowledge investment or knowledge innovation but neglect the synergetic effectiveness of knowledge investment and knowledge innovation that can bring the maximum project value $(\mathrm{Wu}, 2011 \mathrm{~b})$. Therefore, this paper selects the steadiness of knowledge investment and the balance of knowledge innovation as the two control objectives for realizing project values adding from a panoramic view of project values adding. Considering the alternative of effort-cost between knowledge investment and knowledge innovation, this paper examined the effects of inter-organizational knowledge collaboration on project values adding by means of adjusting the incentive intensity in the process of knowledge investment and knowledge innovation as coordinating method.

\section{Model Introduction and Solution}

\subsection{Model Introduction}

To simplify the analysis, here we take owners as dominant enterprises and study how they implement inter-organizational collaborative innovation with contractors. In the processes of inter-organizational collaborative innovation of project-based supply chains, owners hold the absolute control and leadership that the other project-based organizations such as contractors and raw materials suppliers have to assign the knowledge division and cooperation based on the needs of owners. Under this circumstance, How the owners and contractors achieve supply chain inter-organizational collaborative innovation value adding through knowledge investment and knowledge innovation becomes the key considering problem. As referred above, the processes of the inter-organizational collaborative innovation of project-based supply chains mainly consist of knowledge investment and knowledge innovation. Here we assume contractors alone complete all knowledge investment and knowledge innovation, while owners take charge of supervising contractors' work. Through the efforts made by contractors, the knowledge cooperation of the supply chain inter-organizational collaborative innovation is expected to be reached, and finally project values can be achieved. 
We first make several basic assumptions as below:

(1) the effort level of contractors in knowledge investment and knowledge innovation is $a_{i}=\left(a_{1}, a_{2}\right), a_{i}>0$; then the added value function of project values can be formulated as follows:

$$
R\left(a_{1}, a_{2}\right)=A_{1} a_{1}+A_{2} a_{2}+\varphi a_{1} a_{2}+\varsigma
$$

where $A_{1}, A_{2}$ are the output coefficients of effort level in knowledge investment and knowledge innovation, which take $\varphi$ as their correlative coefficient that represents new values created by the synergism of knowledge investment and knowledge innovation. $\varsigma$ is the external random variable affecting project value added. To ensure the Hyers-Ulan stability of the function as above, $\varsigma$ is set to follow normal distribution: $\varsigma \sim N\left(0, \delta^{2}\right)$;

(2) Suppose contractors' effort cost function $C\left(a_{1}, a_{2}\right)$ is a completely monotonically increasing function of $a_{i}$ :

$$
C\left(a_{1}, a_{2}\right)=\frac{1}{2} \eta\left(a_{1}^{2}+2 k a_{1} a_{2}+a_{2}^{2}\right)
$$

where $k$ is the marginal cost substitution rate of contractors' efforts in knowledge investment stage and knowledge innovation stage, which shows the impacts on marginal cost of one stage caused by increase of effort level of the other stages. Since $\frac{\partial C(\cdot)}{\partial a}>0, \frac{\partial^{2} C(\cdot)}{\partial a^{2}}>0$, we assume $-1<k<1$

(3) Project management enterprises are risk-neutral and contractors are risk-averse; suppose contractors' negative utility function is unchangeable with absolutely risk-averse and can be cumulated in space and time;

(4) Contractors' effort level of knowledge investment and knowledge innovation can be measured. We define $x=\left(x_{1}, x_{2}\right), x_{1}=a_{1}+\varepsilon_{1}, x_{2}=a_{2}+\varepsilon_{1}$, as the measurable variable of knowledge investment and knowledge innovation, where $\varepsilon_{i}$ represents the influence of random factors on $x$ with the assumption that $\varepsilon_{1}$ and $\varepsilon_{2}$ are irrelevant and follow normal distributions as: $\varepsilon_{1} \sim N\left(0, \sigma_{1}^{2}\right), \varepsilon_{2} \sim N\left(0, \sigma_{2}^{2}\right) . x_{1}$ can be measured as the indicator of contractors' effort level with the contractors' invested resources and degree of involvement in knowledge collaborative innovation and knowledge investment stage; $x_{2}$ can be measured by the adoption of new technology and new processes;

(5) The linear contract compensation formula provided by project management enterprises for the contractors is:

$$
s=\varpi+\beta_{1} x_{1}+\beta_{2} x_{2}
$$


Where $\Phi$ is the fixed compensation for contractors and is assumed as a constant; $\beta_{1}$ and $\beta_{2}$ are marginal incentive intensity provided by project management enterprises for contractors due to the later' effort in knowledge investment and knowledge innovation, respectively. Based on the above assumptions, contractors' net current incomes expectation utility can be summarized as follows:

$$
U_{1}=s-c(a)-\frac{1}{2} \rho\left(\beta_{1}^{2} \sigma_{1}^{2}+\beta_{2}^{2} \sigma_{2}^{2}\right)
$$

where $\frac{1}{2} \rho\left(\beta_{1}^{2} \sigma_{1}^{2}+\beta_{2}^{2} \sigma_{2}^{2}\right)$ is contractors' risk discount that means contractors choose to give up the income amount of $\frac{1}{2} \rho\left(\beta_{1}^{2} \sigma_{1}^{2}+\beta_{2}^{2} \sigma_{2}^{2}\right)$ to ensure their certain incomes.

Project management enterprises' net present value incomes expectation utility can be formulated:

$$
U_{2}=R-S
$$

Then, the expectation utility of project values added is:

$$
U=R-c(a)-\frac{1}{2} \rho\left(\beta_{1}^{2} \sigma_{1}^{2}+\beta_{2}^{2} \sigma_{2}^{2}\right)
$$

Under the background of asymmetric information, in order to maximize the utility function of project values added, the project management enterprises' collaborative incentive policy making would be determined by $a, \beta$ and $k$ together on contractors' knowledge investment and knowledge innovation:

$$
\begin{array}{ll}
\max _{a_{i}, \beta_{i}, k} U \\
\text { s.t. } & a_{i}, \beta_{i}, k \in \arg \max U_{1} \\
& a_{i}, \beta_{i}, k \in \arg \max U_{2}
\end{array}
$$

\subsection{Model Solution}

We can have two stages to analyze the processes of inter-organizational collaborative innovation of project-based supply chains,. At the first stage, owners decide the incentive amplitude $\beta_{1}$ and $\beta_{2}$ to encourage the contractors on knowledge investment and knowledge innovation. At the second stage, with scenario of given $\beta_{1}$ and $\beta_{2}$, the contractors determine their effort level of $a_{1}$ and $a_{2}$ in knowledge investment and knowledge innovation. Therefore, by the method of inverse solution, the first order condition of the synergetic knowledge incentives of inter-organizational collaborative innovation of project-based supply chains is given as below:

$$
\frac{\partial U_{1}}{\partial a_{1}}=0, \frac{\partial U_{1}}{\partial a_{2}}=0
$$


Substitute Equation (2) and (3) in Equation (4) and calculate their derivatives respectively. Then, according to Equation (8) we get:

$$
\left\{\begin{array}{l}
\beta_{1}-\eta\left(a_{1}+k a_{2}\right)=0 \\
\beta_{2}-\eta\left(a_{2}+k a_{1}\right)=0
\end{array}\right.
$$

Equation (9) can be solved easily:

$$
\left\{\begin{array}{l}
a_{1}=\frac{\beta_{1}-k \beta_{2}}{\eta\left(1-k^{2}\right)} \\
a_{2}=\frac{\beta_{2}-k \beta_{1}}{\eta\left(1-k^{2}\right)}
\end{array}\right.
$$

It can be found from Equation (10) that contractors' effort level of either knowledge investment or knowledge innovation is affected not only by the incentive amplitude at its own stage, but also affected at the other stage. Substitute Equation (1), (2), (9) in Equation (6), accordance with Equation (7), we've found that the first order condition of the synergetic knowledge incentives of inter-organizational collaborative innovation of project-based supply chains after optimization is:

$$
\frac{\partial U}{\partial \beta_{1}}=0, \frac{\partial U}{\partial \beta_{2}}=0
$$

Namely,

$$
\left\{\begin{array}{l}
\beta_{1}=\frac{\left(A_{1}-A_{2} k\right)\left(1-k^{2}\right) \rho \eta^{3} \sigma_{1}^{2}+A_{1} \eta^{2}\left(1-k^{2}\right)+\eta \varphi\left(A_{1}+A_{2} k\right)}{\rho^{2} \eta^{4}\left(1-k^{2}\right)^{2} \sigma_{1}^{2} \sigma_{2}^{2}+\rho \eta^{2}\left(\sigma_{1}^{2}+\sigma_{2}^{2}\right)\left[\eta\left(1-k^{2}\right)+2 k \varphi\right]+\eta^{2}+(\varphi-k \eta)^{2}} \\
\beta_{2}=\frac{\left(A_{2}-A_{1} k\right)\left(1-k^{2}\right) \rho \eta^{3} \sigma_{2}^{2}+A_{2} \eta^{2}\left(1-k^{2}\right)+\varphi \eta\left(A_{2}+A_{1} k\right)}{\rho^{2} \eta^{4}\left(1-k^{2}\right)^{2} \sigma_{1}^{2} \sigma_{2}^{2}+\rho \eta^{2}\left(\sigma_{1}^{2}+\sigma_{2}^{2}\right)\left[\eta\left(1-k^{2}\right)+2 k \varphi\right]+\eta^{2}+(\varphi-k \eta)^{2}}
\end{array}\right.
$$

We specify $A=\frac{\partial^{2} U}{\partial\left(\beta_{1}\right)^{2}}, \quad B=\frac{\partial^{2} U}{\partial \beta_{1} \beta_{2}}, C=\frac{\partial^{2} U}{\partial\left(\beta_{2}\right)^{2}}$ and the second order condition of the synergetic knowledge incentives of inter-organizational collaborative innovation of project-based supply chains after optimization will be:

$$
B^{2}-A C<0, A C<0, B^{2}-A C<0, C<0
$$

Additionally, we have Equation (14):

$$
\left\{\begin{array}{l}
A=\frac{\partial^{2} U}{\partial\left(\beta_{1}\right)^{2}}=-\frac{\eta\left(1-k^{2}\right)+2 k \varphi}{\eta^{2}\left(1-k^{2}\right)^{2}}-\rho \sigma_{1}^{2}<0 \\
B=\frac{\partial^{2} U}{\partial \beta_{1} \beta_{2}}=\frac{1+k^{2}}{\eta^{2}\left(1-k^{2}\right)^{2}}+\frac{k}{\eta\left(1-k^{2}\right)} \\
C=\frac{\partial^{2} U}{\partial\left(\beta_{2}\right)^{2}}=-\frac{\eta\left(1-k^{2}\right)+2 k \varphi}{\eta^{2}\left(1-k^{2}\right)^{2}}-\rho \sigma_{2}^{2}<0
\end{array}\right.
$$


Equation (15) can be obtained:

$$
B^{2}-A C=-\frac{1}{\eta^{2}\left(1-k^{2}\right)}\left[\eta(1-k)\left(1-k^{2}\right)+1+k^{2}-2 k \varphi\right]\left[\eta(k+1)\left(1-k^{2}\right)+k^{2}+1+2 k \varphi\right]-\frac{\eta\left(1-k^{2}\right)+2 k \varphi}{\eta^{2}\left(1-k^{2}\right)^{2}} \rho\left(\sigma_{1}^{2}+\sigma_{2}^{2}\right)<0
$$

According to the maximum value property of binary function, there exists $\beta_{i}^{*}$ making $U$ gets its maximum value. Herein the optimal marginal incentive amplitude provided by project management enterprises to contractors under condition of synergetic knowledge investment and knowledge innovation can be expressed as following:

$$
\left\{\begin{array}{l}
\beta_{1}^{*}=\frac{\left(A_{1}-A_{2} k\right)\left(1-k^{2}\right) \rho \eta^{3} \sigma_{1}^{2}+A_{1} \eta^{2}\left(1-k^{2}\right)+\eta \varphi\left(A_{1}+A_{2} k\right)}{\rho^{2} \eta^{4}\left(1-k^{2}\right)^{2} \sigma_{1}^{2} \sigma_{2}^{2}+\rho \eta^{2}\left(\sigma_{1}^{2}+\sigma_{2}^{2}\right)\left[\eta\left(1-k^{2}\right)+2 k \varphi\right]+\eta^{2}+(\varphi-k \eta)^{2}} \\
\beta_{2}^{*}=\frac{\left(A_{2}-A_{1} k\right)\left(1-k^{2}\right) \rho \eta^{3} \sigma_{2}^{2}+A_{2} \eta^{2}\left(1-k^{2}\right)+\eta \varphi\left(A_{2}+A_{1} k\right)}{\rho^{2} \eta^{4}\left(1-k^{2}\right)^{2} \sigma_{1}^{2} \sigma_{2}^{2}+\rho \eta^{2}\left(\sigma_{1}^{2}+\sigma_{2}^{2}\right)\left[\eta\left(1-k^{2}\right)+2 k \varphi\right]+\eta^{2}+(\varphi-k \eta)^{2}}
\end{array}\right.
$$

Substitute Equation (16) in Equation (10), and the optimal effort level contractors on given synergetic knowledge investment and knowledge innovation will be obtained:

$$
\left\{\begin{array}{l}
a_{1}^{*}=\frac{A_{1} \varphi+\left(A_{1}-A_{2} k\right) \eta+\left(A_{1}-2 A_{2} k+A_{1} k^{2}\right) \rho \eta^{2} \sigma_{1}^{2}}{\rho^{2} \eta^{4}\left(1-k^{2}\right)^{2} \sigma_{1}^{2} \sigma_{2}^{2}+\rho \eta^{2}\left(\sigma_{1}^{2}+\sigma_{2}^{2}\right)\left[\eta\left(1-k^{2}\right)+2 k \varphi\right]+\eta^{2}+(\varphi-k \eta)^{2}} \\
a_{2}^{*}=\frac{A_{2} \varphi+\left(A_{2}-A_{1} k\right) \eta+\left(A_{2}-2 A_{1} k+A_{2} k^{2}\right) \rho \eta^{2} \sigma_{2}^{2}}{\rho^{2} \eta^{4}\left(1-k^{2}\right)^{2} \sigma_{1}^{2} \sigma_{2}^{2}+\rho \eta^{2}\left(\sigma_{1}^{2}+\sigma_{2}^{2}\right)\left[\eta\left(1-k^{2}\right)+2 k \varphi\right]+\eta^{2}+(\varphi-k \eta)^{2}}
\end{array}\right.
$$

\section{Model Analysis and Discussion}

Result 1 . When $k \neq 0$, there exists a linear relation between project management enterprises' optimal marginal incentive amplitude and contractors' optimal effort level on synergetic knowledge investment and knowledge innovation. When $-1<k<0, \beta_{i}$ will increase as $k$ goes up, which means knowledge investment and knowledge innovation are correlated in terms of cost complementation, namely, an increase of incentive amplitude at one of the two stages will boost contractors' effort level at that stage, but diminish that at the other stage. When $0<k<1$, $\beta_{i}$ will decrease as $k$ goes up, which means knowledge investment and knowledge innovation are correlated in terms of cost alternatives, herein, when raising incentive amplitude at either stage will lift contractors effort level at both stages. When $k=0$, the effort cost of knowledge investment and knowledge innovation is independent respectively and no any impact to the effort level at the other stage if the incentive amplitude at one stage is enhanced.

Proof: the partial derivative of $a_{i}$ in Equation (9):

Take $-1<k<0$ and $0<k<1$ substitute in the above equations, and result 1 will be proved.

Result 2. As contractors' effort level of knowledge investment goes up, project values added increase first, and then fall down. The maximum project values added can be reached under 
the synergism of knowledge investment and knowledge innovation. Based on Result 1, project management enterprises will firstly strengthen the incentive amplitude, then decrease incentive amplitude to their control objectives.

Proof:

Take the partial derivative of $a_{i}$ in Equation (6):

$$
\left\{\begin{array}{l}
\frac{\partial U}{\partial a_{1}}=A_{1}+\varphi a_{2}-\beta_{1}\left(1+\rho \eta \sigma_{1}^{2}\right)-\rho k \eta \beta_{2} \sigma_{2}^{2}=0 \\
\frac{\partial U}{\partial a_{2}}=A_{2}+\varphi a_{1}-\beta_{2}\left(1+\rho \eta \sigma_{2}^{2}\right)-\rho k \eta \beta_{1} \sigma_{1}^{2}=0
\end{array}\right.
$$

Substitute Equation (16) and Equation (17) in the above equations, then $\frac{\partial U}{\partial a_{1}}=0, \frac{\partial U}{\partial a_{2}}=0$.

The second order partial derivative of $a_{i}$ shows below:

$$
\left\{\begin{array}{l}
A=\frac{\partial^{2} U}{\partial\left(a_{1}\right)^{2}}=-\eta\left(1+\rho \eta \sigma_{1}^{2}\right)-\rho k^{2} \eta^{2} \sigma_{2}^{2}<0 \\
B=\frac{\partial^{2} U}{\partial a_{1} a_{2}}=\varphi-k \eta\left(1+\rho \eta \sigma_{1}^{2}\right)-\rho k \eta^{2} \sigma_{2}^{2} \\
C=\frac{\partial^{2} U}{\partial\left(a_{2}\right)^{2}}=-k \eta\left(1+\rho \eta \sigma_{2}^{2}\right)-\rho k \eta^{2} \sigma_{1}^{2}<0
\end{array}\right.
$$

Based on the extremism property of binary function, there exists $\left(a_{1}{ }^{*}, a_{2}{ }^{*}\right)$ that makes $U$ reach its maximum value. By considering the value of $k$ and the linear relation between project management enterprises' marginal incentive amplitude and contractors' effort level on the synergism of knowledge investment and knowledge innovation, we can get the result proved.

Result 3. Under the knowledge collaborative innovation of project-based supply chains, project management enterprises' optimal marginal incentive amplitude is the monotonically decreasing function of contractors' risk aversion level $(\rho)$, which means the bigger the $\rho$ gains, the smaller of project management enterprises' incentive amplitude reflects $\left(\beta_{i}\right)$.

Proof:

Make the derivative of $\rho$ in Equation (16), then the result will be proved. 


$$
\left\{\begin{aligned}
\frac{\partial \beta_{1}}{\partial \rho}= & -\frac{\left[A_{1} \eta^{2}(1-k)^{2}+\eta \varphi\left(A_{1}+A_{2} k\right)\right]\left\{2 \rho \eta^{4}\left(1-k^{2}\right)^{2} \sigma_{1}^{2} \sigma_{2}^{2}+\eta^{2}\left(\sigma_{1}^{2}+\sigma_{2}^{2}\right)\left[\eta\left(1-k^{2}\right)+2 k \varphi\right]\right\}}{\left\{\rho^{2} \eta^{4}\left(1-k^{2}\right)^{2} \sigma_{1}^{2} \sigma_{2}^{2}+\rho \eta^{2}\left(\sigma_{1}^{2}+\sigma_{2}^{2}\right)\left[\eta\left(1-k^{2}\right)+2 k \varphi\right]+\eta^{2}+(\varphi-k \eta)^{2}\right\}^{2}} \\
& -\frac{\left(A_{1}-A_{2} k\right)\left(1-k^{2}\right) \eta^{3} \sigma_{1}^{2}\left[\rho^{2} \eta^{4}\left(1-k^{2}\right)^{2} \sigma_{1}^{2} \sigma_{2}^{2} \eta^{2}+(\varphi-k \eta)^{2}\right]}{\left\{\rho^{2} \eta^{4}\left(1-k^{2}\right)^{2} \sigma_{1}^{2} \sigma_{2}^{2}+\rho \eta^{2}\left(\sigma_{1}^{2}+\sigma_{2}^{2}\right)\left[\eta\left(1-k^{2}\right)+2 k \varphi\right]+\eta^{2}+(\varphi-k \eta)^{2}\right\}^{2}}<0 \\
\frac{\partial \beta_{2}}{\partial \rho}= & -\frac{\left[A_{2} \eta^{2}(1-k)^{2}+\eta \varphi\left(A_{2}+A_{1} k\right)\right]\left\{2 \rho \eta^{4}\left(1-k^{2}\right)^{2} \sigma_{1}^{2} \sigma_{2}^{2}+\eta^{2}\left(\sigma_{1}^{2}+\sigma_{2}^{2}\right)\left[\eta\left(1-k^{2}\right)+2 k \varphi\right]\right\}}{\left\{\rho^{2} \eta^{4}\left(1-k^{2}\right)^{2} \sigma_{1}^{2} \sigma_{2}^{2}+\rho \eta^{2}\left(\sigma_{1}^{2}+\sigma_{2}^{2}\right)\left[\eta\left(1-k^{2}\right)+2 k \varphi\right]+\eta^{2}+(\varphi-k \eta)^{2}\right\}^{2}} \\
& -\frac{\left(A_{2}-A_{1} k\right)\left(1-k^{2}\right) \eta^{3} \sigma_{2}^{2}\left[\rho^{2} \eta^{4}\left(1-k^{2}\right)^{2} \sigma_{1}^{2} \sigma_{2}^{2} \eta^{2}+(\varphi-k \eta)^{2}\right]}{\left\{\rho^{2} \eta^{4}\left(1-k^{2}\right)^{2} \sigma_{1}^{2} \sigma_{2}^{2}+\rho \eta^{2}\left(\sigma_{1}^{2}+\sigma_{2}^{2}\right)\left[\eta\left(1-k^{2}\right)+2 k \varphi\right]+\eta^{2}+(\varphi-k \eta)^{2}\right\}^{2}}<0
\end{aligned}\right.
$$

Result 4. Project management enterprises' marginal incentive amplitude is determined not only by the measurability of the exact control objective, but also by the other control objective, given the knowledge collaborative innovation of project-based supply chains. the measurability of contractors' effort level is lower, (i.e. the bigger $\sigma_{1}{ }^{2}$ and $\sigma_{2}{ }^{2}$ ), the smaller the project management enterprises' marginal incentive amplitude.

Proof:

Inference 1. If contractors' effort level of knowledge investment and knowledge innovation can not be measured, then:

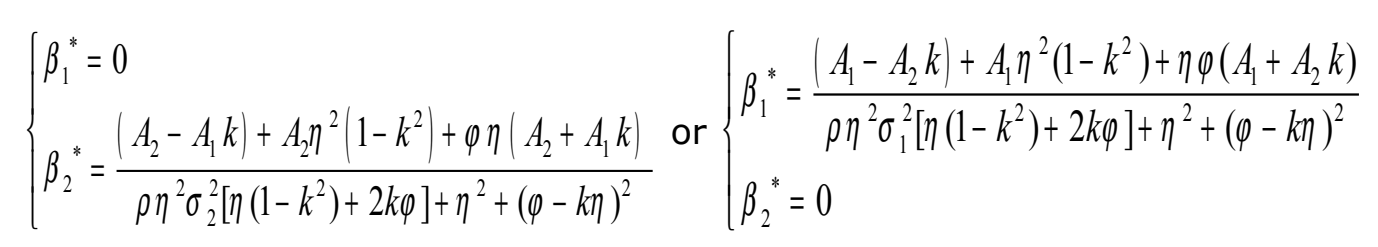

Under this circumstance, the project management enterprises are unable to get information of immeasurable objectives, thus fails to provide effective incentives for contractors. In consequence, the contractors will transfer their efforts and resources used on those immeasurable objectives to other more measurable objectives. In this scenario, the synergism of knowledge investment and knowledge innovation cannot be achieved, and project values added become less than those under the synergism since project management enterprises can incite contractor by their measurable effort level. If $\left(A_{1}-A_{2} k\right)+A_{1} \eta^{2}\left(1-k^{2}\right)+\eta \varphi\left(A_{1}+A_{2} k\right)=0$ or $\left(A_{2}-A_{1} \quad k\right)+A_{2} \quad \eta^{2}\left(1-k^{2}\right)+\varphi \eta\left(A_{2}+A_{1} \quad k\right)=0$, the collaborative relation disintegrates and compensation provided by project management enterprises for contractors is just left $\varpi$. 


$$
\left\{\begin{aligned}
\frac{\partial \beta_{1}^{*}}{\partial\left(\sigma_{1}^{2}\right)=}= & \frac{\left[A_{1} \eta^{2}\left(1-k^{2}\right)+\eta \varphi\left(A_{1}+A_{2} k\right)\right]\left\{\rho^{2} \eta^{4}\left(1-k^{2}\right)^{2} \sigma_{2}^{2}+\rho \eta^{2}\left[\eta\left(1-k^{2}\right)+2 k \varphi\right]\right\}}{\left\{\rho^{2} \eta^{4}\left(1-k^{2}\right)^{2} \sigma_{1}^{2} \sigma_{2}^{2}+\rho \eta^{2}\left(\sigma_{1}^{2}+\sigma_{2}^{2}\right)\left[\eta\left(1-k^{2}\right)+2 k \varphi\right]+\eta^{2}+(\varphi-k \eta)^{2}\right\}^{2}} \\
& -\frac{\left(A_{1}-A_{2} k\right)\left(1-k^{2}\right) \rho \eta^{3}\left\{\rho \eta^{2} \sigma_{2}^{2}\left[\eta\left(1-k^{2}\right)+2 k \varphi\right]+\eta^{2}+(\varphi-k \eta)^{2}\right\}}{\left\{\rho^{2} \eta^{4}\left(1-k^{2}\right)^{2} \sigma_{1}^{2} \sigma_{2}^{2}+\rho \eta^{2}\left(\sigma_{1}^{2}+\sigma_{2}^{2}\right)\left[\eta\left(1-k^{2}\right)+2 k \varphi\right]+\eta^{2}+(\varphi-k \eta)^{2}\right\}^{2}}<0 \\
\frac{\partial \beta_{1}^{*}}{\partial\left(\sigma_{2}^{2}\right)}= & -\frac{\left(A_{1}-A_{2} k\right)\left(1-k^{2}\right) \rho \eta^{3} \sigma_{1}^{2}+A_{1} \eta^{2}\left(1-k^{2}\right)+\eta \varphi\left(A_{1}+A_{2} k\right)}{\rho^{2} \eta^{4}\left(1-k^{2}\right)^{2} \sigma_{1}^{2} \sigma_{2}^{2}+\rho \eta^{2}\left(\sigma_{1}^{2}+\sigma_{2}^{2}\right)\left[\eta\left(1-k^{2}\right)+2 k \varphi\right]+\eta^{2}+(\varphi-k \eta)^{2}} \\
& \times \frac{\left\{\rho^{2} \eta^{4}\left(1-k^{2}\right)^{2} \sigma_{1}^{2}+\rho \eta^{2}\left[\eta\left(1-k^{2}\right)+2 k \varphi\right]\right.}{\rho^{2} \eta^{4}\left(1-k^{2}\right)^{2} \sigma_{1}^{2} \sigma_{2}^{2}+\rho \eta^{2}\left(\sigma_{1}^{2}+\sigma_{2}^{2}\right)\left[\eta\left(1-k^{2}\right)+2 k \varphi\right]+\eta^{2}+(\varphi-k \eta)^{2}}<0 \\
\frac{\partial \beta_{2}^{*}}{\partial\left(\sigma_{1}^{2}\right)}= & -\frac{\left[A_{2} \eta^{2}\left(1-k^{2}\right)+\eta \varphi\left(A_{2}+A_{1} k\right)\right]\left\{\rho^{2} \eta^{4}\left(1-k^{2}\right)^{2} \sigma_{2}^{2}+\rho \eta^{2}\left[\eta\left(1-k^{2}\right)+2 k \varphi\right]\right\}}{\left\{\rho^{2} \eta^{4}\left(1-k^{2}\right)^{2} \sigma_{1}^{2} \sigma_{2}^{2}+\rho \eta^{2}\left(\sigma_{1}^{2}+\sigma_{2}^{2}\right)\left[\eta\left(1-k^{2}\right)+2 k \varphi\right]+\eta^{2}+(\varphi-k \eta)^{2}\right\}^{2}} \\
& -\frac{\left(A_{2}-A_{1} k\right)\left(1-k^{2}\right) \rho \eta^{3}\left\{\rho \eta^{2} \sigma_{2}^{2}\left[\eta\left(1-k^{2}\right)+2 k \varphi\right]+\eta^{2}+(\varphi-k \eta)^{2}\right\}}{\left\{\rho^{2} \eta^{4}\left(1-k^{2}\right)^{2} \sigma_{1}^{2} \sigma_{2}^{2}+\rho \eta^{2}\left(\sigma_{1}^{2}+\sigma_{2}^{2}\right)\left[\eta\left(1-k^{2}\right)+2 k \varphi\right]+\eta^{2}+(\varphi-k \eta)^{2}\right\}^{2}}<0 \\
\frac{\partial \beta_{2}^{*}}{\partial\left(\sigma_{2}^{2}\right)}= & -\frac{\left(A_{2}-A_{1} k\right)\left(1-k^{2}\right) \rho \eta^{3} \sigma_{2}^{2}+A_{2} \eta^{2}\left(1-k^{2}\right)+\eta \varphi\left(A_{2}+A_{1} k\right)}{\rho^{2} \eta^{4}\left(1-k^{2}\right)^{2} \sigma_{1}^{2} \sigma_{2}^{2}+\rho \eta^{2}\left(\sigma_{1}^{2}+\sigma_{2}^{2}\right)\left[\eta\left(1-k^{2}\right)+2 k \varphi\right]+\eta^{2}+(\varphi-k \eta)^{2}} \\
& \times \frac{\left\{\rho^{2} \eta^{4}\left(1-k^{2}\right)^{2} \sigma_{1}^{2}+\rho \eta^{2}\left[\eta\left(1-k^{2}\right)+2 k \varphi\right]\right.}{\rho^{2} \eta^{4}\left(1-k^{2}\right)^{2} \sigma_{1}^{2} \sigma_{2}^{2}+\rho \eta^{2}\left(\sigma_{1}^{2}+\sigma_{2}^{2}\right)\left[\eta\left(1-k^{2}\right)+2 k \varphi\right]+\eta^{2}+(\varphi-k \eta)^{2}}<0
\end{aligned}\right.
$$

Result 5. When the knowledge collaborative innovation of project-based supply chains keep consistence, project management enterprises' marginal incentive amplitude is decided by contractors' effort level at just one stage, but also at the other stage. Suppose contractors' effort level at one stage increases (i.e. $A_{1}$ and $A_{2}$ get bigger), then if $-1<k<0$, project management enterprises' incentive amplitude increases too; if $0<k<1$, project management enterprises' incentive amplitude decreases; if $k=0$, the output efficiency of the objectives is independent respectively. Hence the increase of output efficiency of the control objective has no effect on the incentive amplitude of the other objective.

Proof:

According to Equation (16), we work out the partial derivatives of $A_{1}$ and $A_{2}$ :

$$
\left\{\begin{array}{l}
\frac{\partial \beta_{1}^{*}}{\partial A_{1}}=\frac{\left(1-k^{2}\right) \rho \eta^{3} \sigma_{1}^{2}+\eta^{2}\left(1-k^{2}\right)+\eta \varphi}{\rho^{2} \eta^{4}\left(1-k^{2}\right)^{2} \sigma_{1}^{2} \sigma_{2}^{2}+\rho \eta^{2}\left(\sigma_{1}^{2}+\sigma_{2}^{2}\right)\left[\eta\left(1-k^{2}\right)+2 k \varphi\right]+\eta^{2}+(\varphi-k \eta)^{2}}>0 \\
\frac{\partial \beta_{1}^{*}}{\partial A_{2}}=-\frac{k\left(1-k^{2}\right) \rho \eta^{3} \sigma_{1}^{2}+k \eta \varphi}{\rho^{2} \eta^{4}\left(1-k^{2}\right)^{2} \sigma_{1}^{2} \sigma_{2}^{2}+\rho \eta^{2}\left(\sigma_{1}^{2}+\sigma_{2}^{2}\right)\left[\eta\left(1-k^{2}\right)+2 k \varphi\right]+\eta^{2}+(\varphi-k \eta)^{2}} \\
\frac{\partial \beta_{2}^{*}}{\partial A_{2}}=\frac{\left(1-k^{2}\right) \rho \eta^{3} \sigma_{2}^{2}+\eta^{2}\left(1-k^{2}\right)+\varphi \eta}{\rho^{2} \eta^{4}\left(1-k^{2}\right)^{2} \sigma_{1}^{2} \sigma_{2}^{2}+\rho \eta^{2}\left(\sigma_{1}^{2}+\sigma_{2}^{2}\right)\left[\eta\left(1-k^{2}\right)+2 k \varphi\right]+\eta^{2}+(\varphi-k \eta)^{2}}>0 \\
\frac{\partial \beta_{2}^{*}}{\partial A_{1}}=-\frac{k\left(1-k^{2}\right) \rho \eta^{3} \sigma_{2}^{2}+k \varphi \eta}{\rho^{2} \eta^{4}\left(1-k^{2}\right)^{2} \sigma_{1}^{2} \sigma_{2}^{2}+\rho \eta^{2}\left(\sigma_{1}^{2}+\sigma_{2}^{2}\right)\left[\eta\left(1-k^{2}\right)+2 k \varphi\right]+\eta^{2}+(\varphi-k \eta)^{2}}
\end{array}\right.
$$

Substitute $-1<k<0$ and $0<k<1$ in above equations and the result can be proved. 


\section{Model Simulation and Case Review}

Since contractors' fixed compensation $\varpi$ makes no impact on project management enterprises' incentives or contractors' effort level, we assume that $\varpi=0$. Therefore, the problem we consider here is how to maximize the interest of both project enterprises and contractors when project-based supply chains add values after the cooperation. Based on model assumptions, we define measurable variable $x_{1}$ as contractors' level of participation in knowledge synergism, $x_{2}$ as the level of new processes application, $A_{1}$ and $A_{2}$ are marginal output coefficients at knowledge investment stage and knowledge innovation stage, $\beta_{1}$ as the incentive amplitude provided by project management enterprises for every percent increase of contractors' participation level, $\beta_{2}$ as the incentive compensation obtained by contractors because of new processes application. Here, $\rho=0.6, \sigma_{1}^{2}=0.005, \sigma_{2}^{2}=0.01, A_{1}=45, A_{2}=45, \eta=1$, $\varphi=0.5$.

(1) Relationship between the effort level of knowledge investment and knowledge innovation and project values added

Substitute Equation (9) in Equation (6) and make $\mathrm{k}$ as $-0.5,0$, and 0.5 respectively, we will get three different equations of $U\left(a_{1}, a_{2}\right)$ as follows:

$$
\left\{\begin{array}{l}
U^{1}=45 a_{1}+40 a_{2}-0.50225 a_{1}{ }^{2}-0.503375 a_{2}{ }^{2}+1.0045 a_{1} a_{2} \\
U^{2}=45 a_{1}+40 a_{2}-0.5015 a_{1}{ }^{2}-0.503 a_{2}{ }^{2} \\
U^{3}=45 a_{1}+40 a_{2}-0.50225 a_{1}{ }^{2}-0.503375 a_{2}{ }^{2}-0.0045 a_{1} a_{2}
\end{array}\right.
$$

We simulate the above equations with Matlab7.10 and plotted as shown in Figure 2:

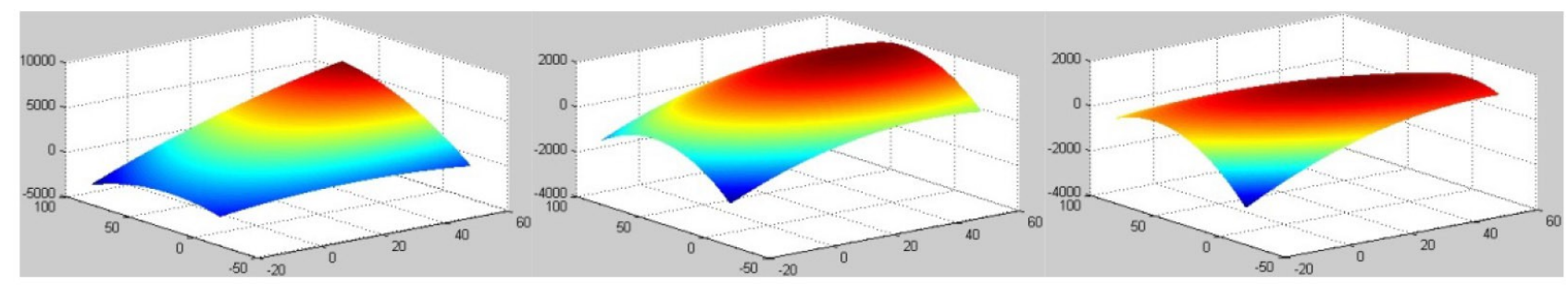

(a) $k=-0.5$

(b) $k=0$

(c) $k=0.5$

Figure 2. Relationship between the Effort Level of Knowledge Investment and Knowledge Innovation and Project Value Added under Different $k$

It can be seen visually that the simulation results under different $k$ values are in line with Result 2. As contractors' effort level of knowledge investment and knowledge innovation goes up, project values added increases first, and then falls down. There exists $\left(a_{1}{ }^{*}, a_{2}{ }^{*}\right)$ that allows project values added reach the maximum.

(2) Relationship between project values added and the incentive amplitude of knowledge investment and knowledge innovation. 
Substitute Equation (9) and related parameters in Equation (6) and make k as $-0.5,0$ and 0.5, we will obtain three different equations of $U\left(a_{1}, a_{2}\right)$ :

$$
\left\{\begin{array}{l}
U^{1}=86 \beta_{1}+83.333 \beta_{2}+1.7778 \beta_{1} \beta_{2}-0.2238 \beta_{1}{ }^{2}-0.2253 \beta_{2}{ }^{2} \\
U^{2}=45 \beta_{1}+40 \beta_{2}+0.5 \beta_{1} \beta_{2}-0.5015 \beta_{1}{ }^{2}-0.503 \beta_{2}{ }^{2} \\
U^{3}=33.778 \beta_{1}+23.333 \beta_{2}+0.5544 \beta_{1} \beta_{2}-1.1126 \beta_{1}{ }^{2}-1.1141 \beta_{2}{ }^{2}
\end{array}\right.
$$

With the same method as above, the simulation results shows in Figure 3 :

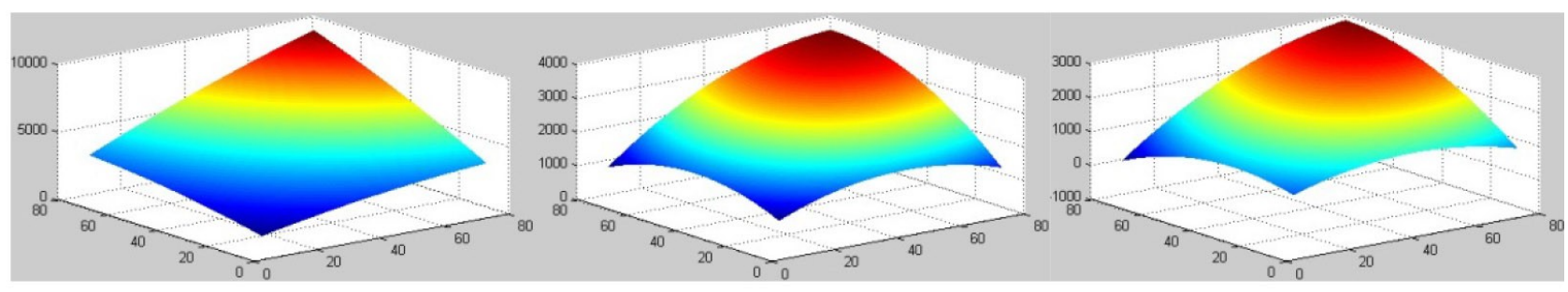

(a) $k=-0.5$ (c) $k=0.5$

Figure 3. Relationship between project values added and the incentive amplitude of knowledge investment and knowledge innovation under different $k$

From Figure 3, we can find it easily that with different $k$ value, simulation results are in accordance with model analysis that is as project management enterprises' incentive amplitude goes up, project values added increase first and then decrease, where exists $\left(\beta_{1}{ }^{*}, \beta_{2}{ }^{*}\right)$ that make project values added reach the maximum.

(3) Relationship between project values added and knowledge investment and knowledge innovation synergism

According to Equation (1), (2), and (6), along with the related parameters, we designated $\mathrm{k}$ with $-0.5,0$, and 0,5 , omitting the influence of contractors' risk discount, we deduce the equations of $R\left(a_{1}, a_{2}\right)$ and $C\left(a_{1}, a_{2}\right)$ respectively as follows:

$$
\left\{\begin{array} { l } 
{ R ^ { 1 } = 4 5 a _ { 1 } + 4 0 a _ { 2 } + 0 . 5 a _ { 1 } a _ { 2 } } \\
{ C ^ { 1 } = 0 . 5 ( a _ { 1 } ^ { 2 } + a _ { 2 } { } ^ { 2 } - a _ { 1 } a _ { 2 } ) }
\end{array} \left\{\begin{array} { l } 
{ R ^ { 2 } = 4 5 a _ { 1 } + 4 0 a _ { 2 } + 0 . 5 a _ { 1 } a _ { 2 } } \\
{ C ^ { 2 } = 0 . 5 a _ { 1 } ^ { 2 } + 0 . 5 a _ { 2 } ^ { 2 } }
\end{array} \left\{\begin{array}{l}
R^{3}=45 a_{1}+40 a_{2}++0.5 a_{1} a_{2} \\
C^{3}=0.5\left(a_{1}^{2}+a_{2}{ }^{2}+a_{1} a_{2}\right)
\end{array}\right.\right.\right.
$$

Related simulated figures are shown as below:

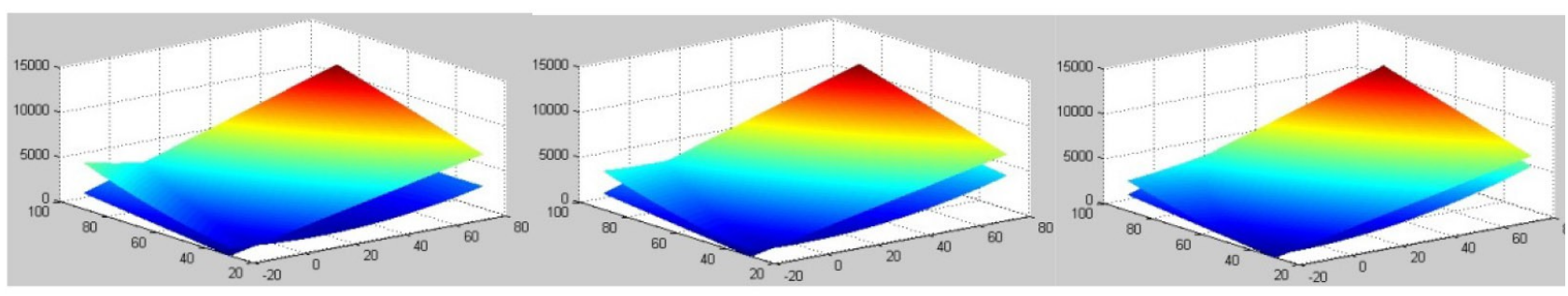

(a) $k=-0.5$

(b) $k=0$

(c) $k=0.5$

Figure 4. Relationship between project values added and knowledge investment and knowledge innovation synergism with different $k$ 
Figure 4 reveals that the influence of knowledge investment and knowledge innovation synergism on project values added varies with different $k$ value. Namely, the bigger the $k$ value, the shorter the distance between $\mathrm{R}$ and $\mathrm{C}$, and the smaller project values added. Under different knowledge investment and knowledge innovation synergetic conditions, the project values added first goes up then fall down, during which process exists a equilibrium point that leads to the maximum of project values added.

(4) Model example of knowledge collaborative incentive of project-based supply chains

Based on the model of knowledge collaborative incentive of project-based supply chains and parameters designated before, we make $\mathrm{k}$ value as $-0.5,0$, and 0.5 , and solve the model. The results including project management enterprises' net incomes, contractors' net incomes and project values added (unite: $10^{4}$ yuan), are listed in Table 1, along with the results acquired by the incentive model that considers single objective for comparison.

\begin{tabular}{|c|c|c|c|c|}
\hline & $\boldsymbol{k}$ & $\begin{array}{c}\text { Knowledge investment and } \\
\text { knowledge innovation } \\
\text { synergism }\end{array}$ & $\begin{array}{c}\text { Knowledge } \\
\text { investment incentive }\end{array}$ & $\begin{array}{c}\text { Knowledge } \\
\text { innovation incentive }\end{array}$ \\
\hline \multirow{3}{*}{$\left(a_{1}, a_{2}\right)$} & -0.5 & $(43.83,41.39)$ & $(56.64,28.32)$ & $(27.93,55.85)$ \\
\hline & 0 & $(53.49,47.64)$ & $(53.49,0)$ & $(0,47.64)$ \\
\hline & 0.5 & $(46.85,40.03)$ & $(74.97,-37.49)$ & $(-36.25,72.51)$ \\
\hline \multirow{3}{*}{$\left(\beta_{1}, \beta_{2}\right)$} & -0.5 & $(23.14,19.47)$ & $(42.48,0)$ & $(0,41.89)$ \\
\hline & 0 & $(53.49,47.64)$ & $(53.49,0)$ & $(0,47.64)$ \\
\hline & 0.5 & $(65.37,60.46)$ & $(56.23,0)$ & $(0,54.38)$ \\
\hline \multirow{3}{*}{$\begin{array}{l}\text { project management } \\
\text { enterprises' net incomes }\end{array}$} & -0.5 & 2436.10 & 1426.30 & 1364.58 \\
\hline & 0 & 2004.30 & 1200.33 & 1127.98 \\
\hline & 0.5 & 890.60 & 697.88 & 648.28 \\
\hline \multirow{3}{*}{ contractors' net incomes } & -0.5 & 2501.11 & 1962.58 & 1426.30 \\
\hline & 0 & 1828.40 & 1127.98 & 943.20 \\
\hline & 0.5 & 908.11 & 864.58 & 856.17 \\
\hline \multirow{3}{*}{ project values added } & -0.5 & 4937.21 & 3388.88 & 2790.88 \\
\hline & 0 & 3832.70 & 2328.31 & 2071.18 \\
\hline & 0.5 & 1798.71 & 1562.46 & 1504.45 \\
\hline
\end{tabular}

Table 1. The comparison among the results of knowledge investment and knowledge innovation synergism and that of single objective incentive models

Table 1 tells us that: (1) under the knowledge collaborative innovation of project-based supply chains, both project management enterprises' implementation of knowledge investment and knowledge collaborative incentive and single objective incentive will raise the project values, and boost the incomes of project management enterprises and contractors; (2) under actual knowledge collaborative innovation of project-based supply chains, no matter the linear relation exists or not between contractors' effort level at knowledge investment stage and knowledge innovation stage, the practice of knowledge investment and knowledge innovation collaborative incentive is more effective than single objective incentive in increasing project 
values added and all participants' net incomes. (3) compared with knowledge investment and knowledge innovation collaborative incentive, single objective incentive actually improve project values added at the cost of the other objectives. For example, when $k=0.5$, contractors effort level at knowledge investment stage is higher than that under knowledge investment and knowledge innovation collaborative incentive, but much lower than that at knowledge innovation stage. (4) under the knowledge collaborative innovation of project-based supply chains, contractors virtually hold higher risk than project management enterprises, which makes contractors get more willing to implement knowledge investment and knowledge innovation collaborative incentive to realize knowledge synergism. Under this circumstance, the incomes of both cooperation parties will increase in different level.

\section{Conclusion}

This paper established and analyzed the knowledge collaborative incentive model based on inter-organizational cooperative innovation of project-based supply chains, in the view of project values added and considering the effort cost alternative of knowledge investment and knowledge innovation. Related simulation and model example were also examined. The results show that under the knowledge collaborative innovation of project-based supply chains, by adjusting incentive amplitude at knowledge investment and knowledge innovation stages, the implementation of collaborative incentive strategy not only can maximize project values added, but also make Pareto improvement for both cooperation parties. All these will urge the contractors allocate the resources and adjust its effort level at knowledge investment and knowledge innovation stages to realize the inter-organizational knowledge synergism of project-based supply chains. However, this paper has just considered the impact of contractors' effort level on project values added, but make it impossible to analyze the scenario where the mutual inter-organizational incentive between participants of project-based supply chains that may optimize project management enterprises' effort level and adjust the resources allocation. Therefore, the inter-organizational bi-lateral incentive of project-based supply chains under knowledge investment and knowledge innovation synergism will be our next key research area to raise project values added further. 


\section{References}

Argote, L.(2000). Knowledge transfer in organizations: learning from the experience of others. Organisational Behavior and Human Decision Process, 82, 1-8. http://dx.doi.org/10.1006/obhd.2000.2883

Barrett, P., \& Sexton, M. (2006). Innovation in small, project-based construction firms. British Journal of Management, 17, 331-346. http://dx.doi.org/10.1111/j.1467-8551.2005.00461.x

Demaid, A., \& Quintas P. (2006). Knowledge across cultures in the construction industry: sustainability, innovation and design. Technovation, 26, 603-610. http://dx.doi.org/10.1016/j.technovation.2005.06.003

Fariborz, M., Fatemeh, S., \& Maryam, G. (2011). Knowledge and Innovation Management Synthesized Model in Learning Organizations. IJEI, 4, 78-85.

Kodama, M. (2005). Knowledge creation through networked strategic communities-case study on new product development in Japanese companies. Long Range Planning, 38, 27-49. http://dx.doi.org/10.1016/j.Irp.2004.11.011

Mohamed, S., \& Anumba C. (2010). Potential for improving site management practices through knowledge management. Construction Innovation, 6, 232-249. http://dx.doi.org/10.1108/14714170610713917

Renzel, B. (2008). Trust in management and knowledge sharing: the mediating efforts of fear and knowledge documentation. Omega, 206-222. http://dx.doi.org/10.1016/j.omega.2006.06.005

Ribeiro, F. (2009). Enhancing knowledge management in construction firms. Construction Innovation: Information, Process, Management, 9, 268-284. http://dx.doi.org/10.1108/14714170910973493

Ribeiro, F. (2005). Using experience based cases to support construction business processes. Proceedings of CIBW78 Conference on Information Technology in Construction, Dresden.

Sammaddar, S. (2006). An analysis of inter-organizational resource sharing decisions in collaborative knowledge creation. European Journal of operational research, 17, 192-210. http://dx.doi.org/10.1016/j.ejor.2004.06.024

Waroonkun, T., \& Stewart, R. (2008). Pathways to enhanced value creation from the international technology transfer process in Thai construction projects. Construction Innovation: Information, Process, Management, 8, 299-317. http://dx.doi.org/10.1108/14714170810912671

Wu, G.D. (2011a). Project-based supply chain cross-organizational cooperative innovation based on the perspective of knowledge flow. Science Research Management, 32, 9-16. 
Wu, G.D. (2011b). Project-based supply chain cross-organizational cooperative incentive mechanism based on knowledge flow. Soft Science, 25, 44-49.

Yim, N., \& Kim H. (2004). Knowledge based decision making on higher strategic concerns: system dynamics approach. Expert Systems with Applications, 27, 143-158. http://dx.doi.org/10.1016/j.eswa.2003.12.019

Journal of Industrial Engineering and Management, 2013 (www.jiem.org)

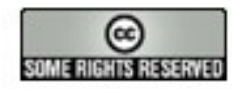

Article's contents are provided on a Attribution-Non Commercial 3.0 Creative commons license. Readers are allowed to copy, distribute and communicate article's contents, provided the author's and Journal of Industrial Engineering and Management's names are included. It must not be used for commercial purposes. To see the complete license contents, please visit http://creativecommons.org/licenses/by-nc/3.0/. 